University of New Orleans

ScholarWorks@UNO

$3-2004$

\title{
New Magnetic Materials Obtained by lon-exchange Reactions from Non-magnetic Layered Perovskites
}

H Kageyama

L Viciu

Gabriel Caruntu

University of New Orleans, gcaruntu@uno.edu

Y Ueda

John B. Wiley

University of New OReans, jwiley@uno.edu

Follow this and additional works at: https://scholarworks.uno.edu/chem_facpubs

Part of the Chemistry Commons

\section{Recommended Citation}

J. Phys.: Condens. Matter 16 (2004) S585-S590

This Article is brought to you for free and open access by the Department of Chemistry at ScholarWorks@UNO. It has been accepted for inclusion in Chemistry Faculty Publications by an authorized administrator of ScholarWorks@UNO.For more information, please contact scholarworks@uno.edu. 
New magnetic materials obtained by ion-exchange reactions from non-magnetic layered perovskites

This article has been downloaded from IOPscience. Please scroll down to see the full text article.

2004 J. Phys.: Condens. Matter 16 S585

(http://iopscience.iop.org/0953-8984/16/11/003)

View the table of contents for this issue, or go to the journal homepage for more

Download details:

IP Address: 137.30.164.204

The article was downloaded on 05/03/2013 at 20:30

Please note that terms and conditions apply. 


\title{
New magnetic materials obtained by ion-exchange reactions from non-magnetic layered perovskites
}

\author{
H Kageyama ${ }^{1,2,3,4}$, L Viciu ${ }^{2}$, G Caruntu ${ }^{2}$, Y Ueda ${ }^{3}$ and J B Wiley ${ }^{2}$ \\ ${ }^{1}$ Department of Chemistry, Graduate School of Science, Kyoto University, \\ Kyoto 606-8502, Japan \\ 2 Department of Chemistry and the Advanced Materials Research Institute, \\ University of New Orleans, New Orleans, LA 70148-2820, USA \\ ${ }^{3}$ Institute for Solid State Physics, University of Tokyo, Kashiwa, Chiba 277-8581, Japan \\ E-mail: kage@kuchem.kyoto-u.ac.jp
}

Received 7 January 2004

Published 4 March 2004

Online at stacks.iop.org/JPhysCM/16/S585 (DOI: 10.1088/0953-8984/16/11/003)

\begin{abstract}
New layered magnetic materials, $(\mathrm{MCl}) \mathrm{Ca}_{2} \mathrm{Ta}_{3} \mathrm{O}_{10}(\mathrm{M}=\mathrm{Cu}, \mathrm{Fe})$, have been prepared by ion-exchange reactions of non-magnetic perovskite derivatives, $\mathrm{ACa}_{2} \mathrm{Ta}_{3} \mathrm{O}_{10}(\mathrm{~A}=\mathrm{Rb}, \mathrm{Li})$, in corresponding anhydrous molten salts. Powder $\mathrm{x}$-ray diffraction patterns of the products are successfully indexed assuming tetragonal symmetry with cell dimensions $a=3.829 \AA$ and $c=15.533 \AA$ for $\mathrm{Cu}$, and $a=3.822 \AA$ and $c=15.672 \AA$ for Fe. Being separated by the $\mathrm{Ca}_{2} \mathrm{Ta}_{3} \mathrm{O}_{10}$ triple-layer perovskite slabs, the transition-metal chloride $(\mathrm{MCl})$ network provides a two-dimensional magnetic lattice. Magnetic susceptibility measurements show that $(\mathrm{CuCl}) \mathrm{Ca}_{2} \mathrm{Ta}_{3} \mathrm{O}_{10}$ is in an antiferromagnetic state below $8 \mathrm{~K}$, while $(\mathrm{FeCl}) \mathrm{Ca}_{2} \mathrm{Ta}_{3} \mathrm{O}_{10}$ has two anomalies at 91 and $125 \mathrm{~K}$, suggesting successive phase transitions due to geometrical spin frustration.
\end{abstract}

\section{Introduction}

Geometrical spin frustration has received considerable interest from solid-state physicists over the last several decades. They have investigated models mostly comprising of rigid triangles with only one exchange interaction, including pyrochlore, Kagomé and triangular lattices, while little attention has been paid to systems based on squares [1]. Among the latter cases are the Shastry-Sutherland model [2] and the $J_{1}-J_{2}$ model [3], both of which contain two distinct exchange interactions (see figure 1). In order to exploit inorganic materials with frustrated magnetic geometry, one usually takes the solid-state reaction route. This approach, however, can limit the control of specific structural features to only those obtainable within the bounds of a specific structure type (e.g. spinel or corundum).

4 Permanent address: Department of Chemistry, Graduate School of Science, Kyoto University, Kyoto 606-8502, Japan. 
(a)

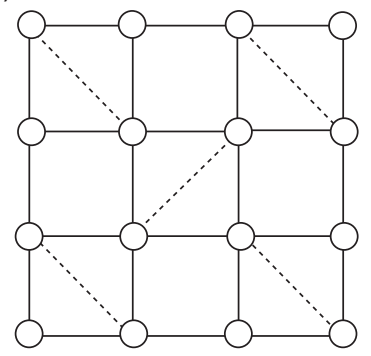

(b)

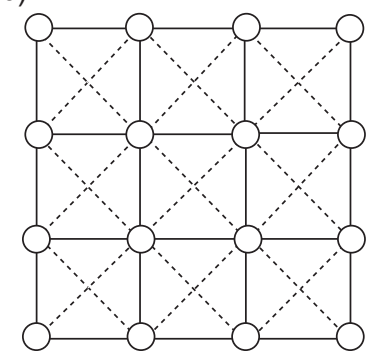

Figure 1. (a) Shastry-Sutherland model and (b) the $J_{1}-J_{2}$ model. With inclusion of diagonal bonds (broken lines) to the square lattice, magnetic moments sitting on the corners (open circles) feel frustration.

Recently, low-temperature topotactic strategies such as intercalation/deintercalation have been found to be very effective for the design and construction of new magnetic materials. Some of the authors and their collaborators obtained $(\mathrm{CuX}) \mathrm{LaNb}_{2} \mathrm{O}_{7}(\mathrm{X}=\mathrm{Cl}, \mathrm{Br})$ from a non-magnetic double-layer perovskite host $\mathrm{RbLaNb}_{2} \mathrm{O}_{7}$ through an ion-exchange reaction with $\mathrm{CuX}_{2}$ [4]. They further reported, using similar synthetic routes, the synthesis of a series of related materials, $(\mathrm{CuX}) \mathrm{LaTa}_{2} \mathrm{O}_{7},(\mathrm{CuCl}) \mathrm{Ca}_{2} \mathrm{Nb}_{3} \mathrm{O}_{10},(\mathrm{FeCl}) \mathrm{LaNb}_{2} \mathrm{O}_{7}$ and so on [5-7]. In all compounds, the transition-metal ions carrying magnetic moments form layers of a two-dimensional square lattice, separated by magnetically inert perovskite slabs. Since each halogen ion is located at the centre of a square made by the neighbouring four magnetic ions, the nearest and next-nearest interactions are expected to be comparable. If this is the case, the magnetic properties are mapped onto the $J_{1}-J_{2}$ model. In addition, these interactions appear to be tunable by modifying, for example, the size of perovskite slabs. Herein, we present the synthesis and magnetic character of the new magnetic materials $(\mathrm{CuCl}) \mathrm{Ca}_{2} \mathrm{Ta}_{3} \mathrm{O}_{10}$ and $(\mathrm{FeCl}) \mathrm{Ca}_{2} \mathrm{Ta}_{3} \mathrm{O}_{10}$, the structures of which are likely to be isostructural with $(\mathrm{CuCl}) \mathrm{Ca}_{2} \mathrm{Nb}_{3} \mathrm{O}_{10}$.

\section{Experimental details}

A triple-layered Dion-Jacobson phase, $\mathrm{RbCa}_{2} \mathrm{Ta}_{3} \mathrm{O}_{10}$, was prepared by a solid-state reaction method from $\mathrm{Rb}_{2} \mathrm{CO}_{3}$ (Alfa, 99\%), $\mathrm{CaCO}_{3}$ (Alfa, 99.99\%) and $\mathrm{Ta}_{2} \mathrm{O}_{5}$ (Alfa, 99.999\%). Stoichiometric quantities of $\mathrm{CaCO}_{3}$ and $\mathrm{Ta}_{2} \mathrm{O}_{5}$ with a $25 \%$ molar excess of $\mathrm{Rb}_{2} \mathrm{CO}_{3}$ were weighed and ground thoroughly inside an argon-filled glove box, annealed overnight at $850{ }^{\circ} \mathrm{C}$ followed by an additional thermal treatment at $1050^{\circ} \mathrm{C}$ for $24 \mathrm{~h}$. The excess of $\mathrm{RbCO}_{3}$ was added to balance that lost due to volatilization. The product was washed with distilled water and dried at $150{ }^{\circ} \mathrm{C}$ overnight. $\mathrm{LiCa}_{2} \mathrm{Ta}_{3} \mathrm{O}_{10}$ was obtained by an ion exchange reaction from $\mathrm{LiNO}_{3}$ (Alfa, 99.98\%) and $\mathrm{RbCa}_{2} \mathrm{Ta}_{3} \mathrm{O}_{10}$ in a $10: 1$ molar ratio at $300^{\circ} \mathrm{C}$. After $24 \mathrm{~h}$, the product was thoroughly washed with warm water and acetone and then dried at $150^{\circ} \mathrm{C}$ overnight. To prepare $(\mathrm{MCl}) \mathrm{Ca}_{2} \mathrm{Ta}_{3} \mathrm{O}_{10}(\mathrm{M}=\mathrm{Cu}, \mathrm{Fe}), \mathrm{ACa}_{2} \mathrm{Ta}_{3} \mathrm{O}_{10}(\mathrm{~A}=\mathrm{Li}, \mathrm{Rb})$ were mixed with a two-fold molar excess of ultra-dry $\mathrm{MCl}_{2}$ (Alfa, 99.99\%) and then pressed into pellets with a hand press inside an argon-filled glove box. Reactions were carried out in sealed, evacuated $\left(<10^{-3}\right.$ Torr $)$ Pyrex tubes at $320^{\circ} \mathrm{C}$ for 7 days and $350^{\circ} \mathrm{C}$ for 12 days for $\mathrm{M}=\mathrm{Cu}$ and $\mathrm{Fe}$, respectively. The final products were washed with warm water and acetone to eliminate the excess copper chloride and alkali metal by-product.

Chemical analyses were based on energy dispersive spectroscopy (EDS) of sets of individual grains. These are carried out on a JEOL (model JSM-5410) scanning electron microscope (SEM) equipped with an EDAX (DX-PRIME) microanalytical system. X-ray 


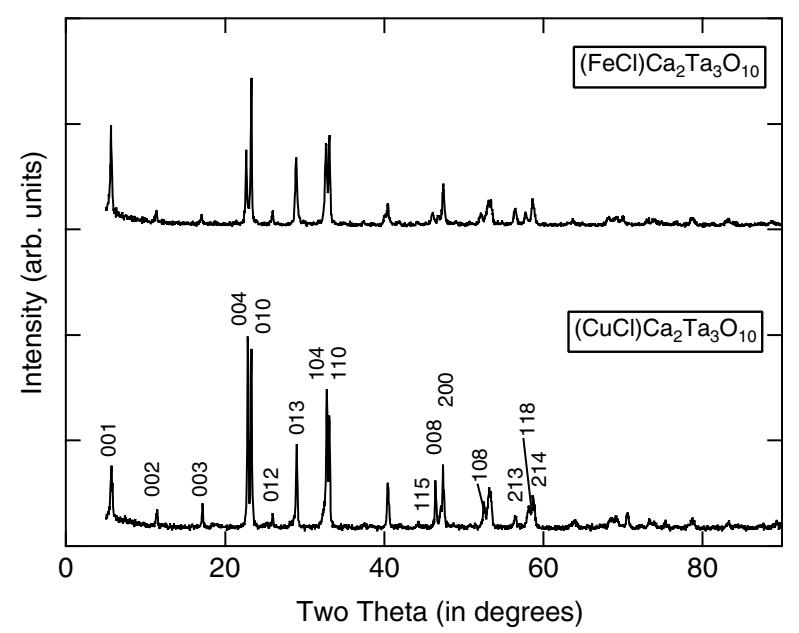

Figure 2. Powder $\mathrm{x}$-ray diffraction patterns for (lower) $(\mathrm{CuCl}) \mathrm{Ca}_{2} \mathrm{Ta}_{3} \mathrm{O}_{10}$ and (upper) $(\mathrm{FeCl})$ $\mathrm{Ca}_{2} \mathrm{Ta}_{3} \mathrm{O}_{10}$.

powder diffraction data were collected on a Philips X'Pert-MPD diffractometer equipped with a graphite monochromator and $\mathrm{Cu} \mathrm{K} \alpha(\lambda=1.5418 \AA)$. The pattern was recorded in stepscanning mode between $5^{\circ}$ and $90^{\circ}$ with a $0.02^{\circ}$ step width and step time of $1 \mathrm{~s}$. Unit cells were refined by a least-squares method with a homemade program, which runs on a Macintosh computer. Magnetic susceptibility measurements were carried out with a superconducting quantum interference device (SQUID) magnetometer (Quantum Design, MPMS) over the temperature range $2-300 \mathrm{~K}$ in an applied field of $H=0.1 \mathrm{~T}$.

\section{Result and discussion}

The synthesis of $(\mathrm{MCl}) \mathrm{Ca}_{2} \mathrm{Ta}_{3} \mathrm{O}_{10}(\mathrm{M}=\mathrm{Cu}, \mathrm{Fe})$ is achieved by a single-step ion exchange reaction involving the replacement of the alkali-metal cation $\mathrm{A}$ of the perovskite host, $\mathrm{ACa}_{2} \mathrm{Ta}_{3} \mathrm{O}_{10}$, by $\mathrm{M}^{2+}$ and $\mathrm{Cl}^{-}$:

$$
\mathrm{ACa}_{2} \mathrm{Ta}_{3} \mathrm{O}_{10}+\mathrm{MCl}_{2} \rightarrow(\mathrm{MCl}) \mathrm{Ca}_{2} \mathrm{Ta}_{3} \mathrm{O}_{10}+\mathrm{ACl}
$$

Figure 2 presents $x$-ray diffraction patterns at room temperature for $(\mathrm{CuCl}) \mathrm{Ca}_{2} \mathrm{Ta}_{3} \mathrm{O}_{10}$ and $(\mathrm{FeCl}) \mathrm{Ca}_{2} \mathrm{Ta}_{3} \mathrm{O}_{10}$ obtained from $\mathrm{LiCa}_{2} \mathrm{Ta}_{3} \mathrm{O}_{10}$ and $\mathrm{RbCa}_{2} \mathrm{Ta}_{3} \mathrm{O}_{10}$, respectively. Both profiles could be readily indexed on tetragonal unit cells and no trace of the impurity phase was found within the experimental resolution of the present experiment. The final products are green and light brown in colour for the $\mathrm{Cu}$ and $\mathrm{Fe}$ compounds, respectively. The EDX experiment revealed that no residual alkali metal is present in the products and the $\mathrm{M}: \mathrm{Cl}: \mathrm{Ca}$ compositions were approximately found to be $1: 1: 2$.

It is to be noted that, when $\mathrm{RbCa}_{2} \mathrm{Ta}_{3} \mathrm{O}_{10}$ and $\mathrm{LiCa}_{2} \mathrm{Ta}_{3} \mathrm{O}_{10}$ were used as the hosts in the formation of $(\mathrm{CuCl}) \mathrm{Ca}_{2} \mathrm{Ta}_{3} \mathrm{O}_{10}$ and $(\mathrm{FeCl}) \mathrm{Ca}_{2} \mathrm{Ta}_{3} \mathrm{O}_{10}$, respectively, the products were of poor quality in that the reactions were incomplete, the products were poorly crystalline and a minor impurity was formed. It is known in many Dion-Jacobson-type layer perovskites that alkali-metal cation mobilities within the hosts are greater for the smaller alkali metals and hence correlate highly with the reaction time $[5,7,8]$. This tendency is consistent with what happened in $(\mathrm{CuCl}) \mathrm{Ca}_{2} \mathrm{Ta}_{3} \mathrm{O}_{10}$, but not in $(\mathrm{FeCl}) \mathrm{Ca}_{2} \mathrm{Ta}_{3} \mathrm{O}_{10}$. Further study is needed to clarify the origin of the discrepancy in the latter compound. It may be possible that the 


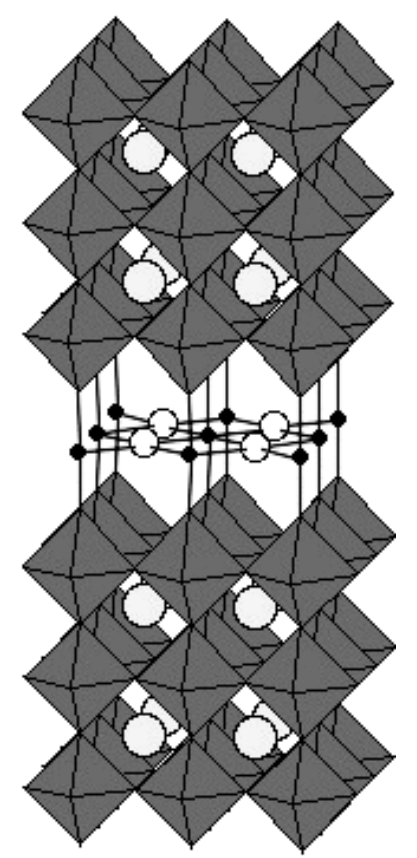

Figure 3. Idealized structural representation of $(\mathrm{MCl}) \mathrm{Ca}_{2} \mathrm{Ta}_{3} \mathrm{O}_{10}(\mathrm{M}=\mathrm{Cu}, \mathrm{Fe})$ with the $\mathrm{MCl}$ layer sandwiched by slabs of corner-sharing $\mathrm{TaO}_{6}$ octahedra. The white, grey and black spheres are chlorines, calciums and coppers/irons, respectively.

Table 1. Tetragonal unit cell parameters for the parents and the exchange products.

\begin{tabular}{llll}
\hline Compounds & $a(\AA)$ & $c(\AA)$ & Cell volume $\left(\AA^{3}\right)$ \\
\hline $\mathrm{RbCa}_{2} \mathrm{Ta}_{3} \mathrm{O}_{10}$ & $3.857(3)$ & $15.044(3)$ & 223.8 \\
$\mathrm{LiCa}_{2} \mathrm{Ta}_{3} \mathrm{O}_{10}$ & $3.851(1)$ & $28.339(2)^{\mathrm{a}}$ & 420.3 \\
$(\mathrm{CuCl}) \mathrm{Ca}_{2} \mathrm{Ta}_{3} \mathrm{O}_{10}$ & $3.829(3)$ & $15.533(4)$ & 227.7 \\
$(\mathrm{FeCl}) \mathrm{Ca}_{2} \mathrm{Ta}_{3} \mathrm{O}_{10}$ & $3.822(3)$ & $15.672(4)$ & 228.9 \\
\hline
\end{tabular}

a Due to staggered stacking of perovskite slabs, the $c$ in $\mathrm{LiCa}_{2} \mathrm{Ta}_{3} \mathrm{O}_{10}$ is nearly double relative to the other compounds. Thus, the spacing between Li ions in successive layers is $14.169 \AA$.

diffusion of reactants to and products away from the reaction interface is more important than cation mobilities.

As seen in table 1, unit cells obtained from the analysis show that the spacing between the perovskite layers is expanded significantly on reaction relative to the starting materials. Moreover, the observed patterns without any extinct reflections are quite similar to those of the known $(\mathrm{CuCl}) \mathrm{Ca}_{2} \mathrm{Nb}_{3} \mathrm{O}_{10}(\mathrm{P} 4 / \mathrm{mmm})$ [5], except for slight differences in peak positions due to small variations in cell parameters. This indicates that the two compounds should be isostructural with $(\mathrm{CuCl}) \mathrm{Ca}_{2} \mathrm{Nb}_{3} \mathrm{O}_{10}$. It is known from structural studies that the increase observed in $c$ is due to the formation of extended metal-halide arrays between the perovskite layers [4-7]. The divalent metal cations (M) bridge between apical oxygens of the perovskite layers while surrounded by four chloride ions: the octahedra edge-share with each other and corner-share with the octahedra of the perovskite layers. Figure 3 illustrates an idealized crystal structure. 


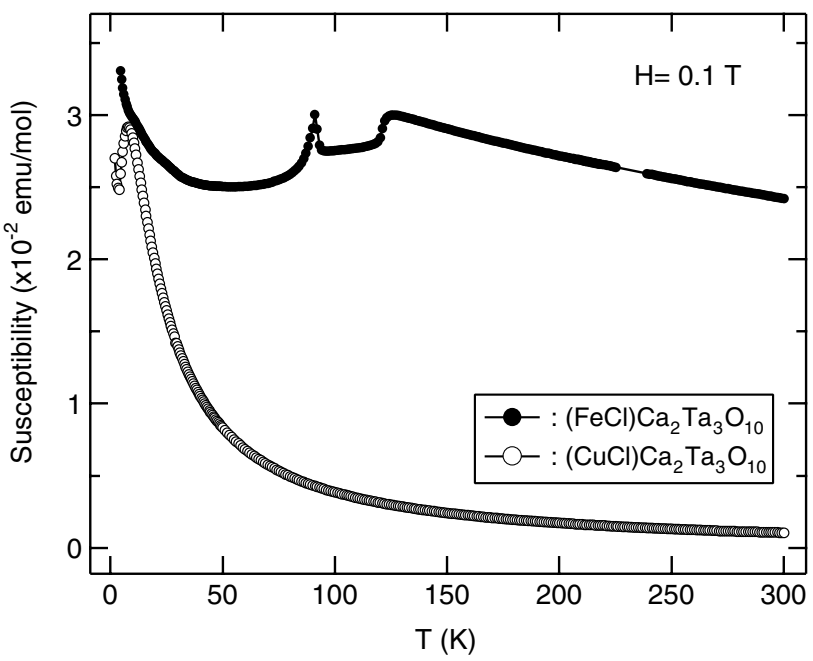

Figure 4. The temperature variation of the molar susceptibility of $(\mathrm{CuCl}) \mathrm{Ca}_{2} \mathrm{Ta}_{3} \mathrm{O}_{10}$ (open) and ( $\mathrm{FeCl}) \mathrm{Ca}_{2} \mathrm{Ta}_{3} \mathrm{O}_{10}$ (full).

In figure 4, we show a plot of magnetization versus temperature for $(\mathrm{CuCl}) \mathrm{Ca}_{2} \mathrm{Ta}_{3} \mathrm{O}_{10}$. The high-temperature data $(T>170 \mathrm{~K})$ demonstrate the Curie-Weiss behaviour with an effective magnetic moment $\left(P_{\text {eff }}\right)$ of $1.65 \mu_{\mathrm{B}}$ and a Weiss temperature $(\theta)$ of $26 \mathrm{~K}$. The $P_{\text {eff }}$ value is nearly consistent with the presence of $\mathrm{Cu}^{2+}$ ions $(S=1 / 2)$ in a stoichiometric composition. The ferromagnetic interactions within the $\mathrm{CuCl}$ layer are derived from the positive value of $\theta$. The compound shows an antiferromagnetic long-range ordering at $T_{\mathrm{N}}=8 \mathrm{~K}$. The magnetic structure is possibly composed of antiferromagnetic stacking of ferromagnetic layers. To support this magnetic structure, additional experiments such as neutron diffraction are necessary. It is worth pointing out that the triple-layered niobate $(\mathrm{CuCl}) \mathrm{Ca}_{2} \mathrm{Nb}_{3} \mathrm{O}_{10}$ has a similar Néel temperature $\left(T_{\mathrm{N}}=10 \mathrm{~K}\right)$ [5], while the double-layered one $(\mathrm{CuCl}) \mathrm{LaNb}_{2} \mathrm{O}_{7}$ has a maximum susceptibility at a somewhat higher temperature $(16 \mathrm{~K})$, accompanied by an unusually sharp drop with decreasing temperature [6]. The spacing between magnetic layers appears to play a crucial role in the magnetic character of these compounds.

The magnetic susceptibility of the $\mathrm{M}=\mathrm{Fe}$ compound, shown in figure 4, exhibits a more complex behaviour. Above $150 \mathrm{~K}$, a Curie-Weiss law fit indicates that antiferromagnetic interactions are dominant. On cooling, the susceptibility shows a drop at $125 \mathrm{~K}$, which is followed by a cusp at $91 \mathrm{~K}$. This is an implication of successive magnetic phase transitions, possibly arising from the competition between $J_{1}$ and $J_{2}$. A similar behaviour can be found in $(\mathrm{FeCl}) \mathrm{LaNb}_{2} \mathrm{O}_{7}$, although the niobate compound has lower transition temperatures, 18 and $87 \mathrm{~K}$ [7]. Determination of the magnetic structures for $(\mathrm{FeCl}) \mathrm{Ca}_{2} \mathrm{Ta}_{3} \mathrm{O}_{10}$, as well as a qualitative and quantitative comparison with the niobate compounds, are important and are now in progress.

\section{Conclusion}

We have prepared layered magnetic materials, $(\mathrm{CuCl}) \mathrm{Ca}_{2} \mathrm{Ta}_{3} \mathrm{O}_{10}$ and $(\mathrm{FeCl}) \mathrm{Ca}_{2} \mathrm{Ta}_{3} \mathrm{O}_{10}$, using non-magnetic perovskite-based hosts through the topotactic ion-exchange reactions. This synthetic approach has an important advance to offer a wide variety of new magnetic materials. 
Construction of different magnetic topologies, for instance the triangular lattice, could be realized if a host with hexagonal symmetry is chosen.

\section{Acknowledgments}

This work was supported by the Ministry of Education, Culture, Sports, Science and Technology (MECSST) of Japan through Grant-in-Aid for Scientific Research no. 40302640, the National Science Foundation DMR-9983591 and DMR-0309972. HK and his family appreciated the warm hospitality they received from the people at the University of New Orleans during their stay between January and March in 2003, which was also supported by the MECSST. In particular, HK would like to express his sincere thanks to Dr W Zhou for help in experiments and to Ms K Tran for her continuous efforts to facilitate daily life in the USA.

\section{References}

[1] Kageyama H, Mushnikov N V, Yamada M, Goto T and Ueda Y 2003 Physica B 3291020

[2] Kageyama H, Yoshimura K, Stern R, Mushnikov N, Onizuka K, Kato M, Kosuge K, Slichter C, Goto T and Ueda Y 1999 Phys. Rev. Lett. 823168

[3] Melzi P, Carretta P, Lascialfari A, Mambrini M, Troyer M, Millet P and Mila F 2000 Phys. Rev. Lett. 851318

[4] Kodenkandath T A, Lalena J, Zhou W L, Carpenter E, Sangregorio C, Falster A, Simmons W, O'Connor C and Wiley J B 1999 J. Am. Chem. Soc. 12110743

[5] Kodenkandath T A, Kumbhar A S, Zhou W L and Wiley J B 2001 Inorg. Chem. 40710

[6] Viciu L, Caruntu G, Royant N, Koenig J, Zhou W L, Kodenkandath T A and Wiley J B 2002 Inorg. Chem. 41 3385

[7] Viciu L, Koenig J, Spinu L, Zhou W L and Wiley J B 2003 Chem. Mater. 151480

[8] Sato M, Abo J, Jin T and Ohta M 1993 J. Alloys Compounds 19281 